\title{
UJI EFIKASI EKSTRAK BANDOTAN (Ageratum conyzoides L.) TERHADAP FREKUENSI DAN INTENSITAS SERANGAN HAMA ULAT Plutella xylostella L. PADA TANAMAN LOBAK (Rhapanus sativus L.).
}

(Bandotan Extract Efficacy Test (Ageratum conyzoides L.)Against The Frequency And Intensity Of Caterpillar Pest Attack Plutella xylostella L. In Radish Plant (Rhapanus sativus L.).

\author{
Helda Syahfari ${ }^{1}$, Siti Raudah Oktaviani ${ }^{2}$, Hery Sutejo ${ }^{1}$. \\ ${ }^{1}$ Fakultas Pertanian Universitas 17 Agustus 1945 Samarinda \\ ${ }^{2}$ Mahasiswa Fakultas Pertanian Universitas 17 Agustus 1945 Samarinda \\ Corresponding author : helda_syahfari@yahoo.co.id,
}

Article Submitted: 05-12-2020

Article Accepted: 08-01-2021

\begin{abstract}
Purpose of the research was to determine the appropriate method for testing the concentration of bandotan extract (Ageratum conyzoides L.) to reduce the frequency and intensity of Plutella xylostela L. The research carried out from March to June 2020 on the planting area of SMK-SPP Negeri Samarinda, Samarinda, East Kalimantan from March to June 2020. It applied Completely Randomized Design (CRD) with five treatment of bandotan extract (B) vegetable pesticide and 8 replications, namely : control (b0), $10 \mathrm{ml} \mathrm{L}^{-1}$ (b1), $20 \mathrm{ml} \mathrm{L}^{-1}$ (b2), $30 \mathrm{ml} \mathrm{L} \mathrm{L}^{-1}$ (b3), and $40 \mathrm{ml} \mathrm{L}^{-1}$ (b4). Results of the research showed that : (1) the treatment of bandotan extract was affected significantly until very significantly on the attack frequency at 21 and 35 days after planting, intensity of attack at 21 and 35 days after planting; (2) Bandotan extract acts as a botanical insecticide against Pluttella xylostella $\mathrm{L}$. caterpillars the higher the concentration of bandotan extract given, the lower the frequency and intensity of Pluttela xylostella L pest attack on radish plants; and (3) the concentration of bandotan extract that can suppress the Pluttella xylostella L. caterpillar is at a concentration of $40 \mathrm{ml} \mathrm{L}^{-}$.
\end{abstract}

Keywords: Badotan Extract, Plutella xylostella L. Radish plant

\section{PENDAHULUAN}

Hama krop kubis (Pluttela xylostella L.) merupakan jenis hama penting pada tanaman lobak dan berbagai jenis sayuran suku kubis-kubisan. Serangga yang termasuk dalam famili Plutellidae, ordo Lepidoptera tersebut memiliki ciri-ciri yaitu larva berukuran kecil $( \pm 0,33$ inci ketika tumbuh penuh), tubuh melebar di bagian tengah dan meruncing ke arah anterior dan posterior dengan dua proleg pada segmen terakhir (posterior) membentuk huruf $\mathrm{V}$. (Kalshoven,1981; Harjaka dan Suryanti, 2002). Hama ini meletakkan telur di dekat urat daun pada permukaan daun, larva yang baru menetas memakan bagian dalam jaringan daun, sehingga menimbulkan gejala yang khas pada daun (Anonim, 2010).

Menurut Tarigan, dkk. (2012), penggunaan pestisida nabati atau senyawa bioaktif alamiah yang berasal dari tumbuhan merupakan salah satu komponen pengendalian hama dan penyakit terpadu ramah lingkungan. Selain menghasilkan senyawa primer, dalam proses metabolismenya tumbuhan juga menghasilkan senyawa lain. Senyawa sekunder ini merupakan pertahanan tumbuhan terhadap serangan hama. Tumbuhan adalah sumber bahan kimia 
potensial yang dapat digunakan sebagai pestisida yang ramah lingkungan dan lebih aman secara kesehatan (Wiratno \& Trisawa, 2012). Di Indonesia bahan pestisida nabati sebanyak 37.000 spesies flora yang telah teridentifikasi dan baru $1 \%$ yang telah dimanfaatkan (Julaily, dkk. 2013).

Pengendalian hama Pluttela xylostella L. yang ramah lingkungan dan aman untuk kesehatan masyarakat maka dipilih pestisida alternatif dari bahan alami yang mempunyai senyawa bioaktif salah satunya adalah daun tumbuhan bandotan (Ageratum conyzoides L.). Bandotan merupakan gulma yang mudah ditemukan di sawah, kebun, perkarangan rumah dan pinggir jalan. Bagian daun bandotan memiliki senyawa bioaktif yang berfungsi sebagai insektisida, nematisida, antinematoda, antibakterial dan dapat digunakan sebagai penghambat perkembangan organisme. Kandungan senyawa bioaktif tersebut diantaranya saponin, flavanoid, polifenol, dan minyak atsiri yang mampu mencegah hama mendekati tumbuhan (penolak) dan penghambat larva menjadi pupa. (Kinasih, 2013).

Tujan penelitian adalah untuk mengetahui metode pengujian konsentrasi ekstrak bandotan (Ageratum conyzoides L.) yang tepat dan untuk menekan tingkat frekuensi dan intensitas serangan hama Plutella xylostela $\mathrm{L}$.

\section{METODOLOGI PENELITIAN}

\section{Tempat dan Waktu}

Penelitian dilaksanakan dari bulan Maret sampai dengan Juni 2020 pada lahan Pertanaman SMK-SPP Negeri Samarinda, Samarinda Kalimantan Timur.

\section{Bahan dan Alat}

Bahan penelitian yaitu: daun Bandotan , benih tanaman lobak varietas Minghao, tanah lapisan atas, aquades, pupuk kandang. Alat yang digunakan yaitu: polibag, plang nama, meteran, alat tulis, gembor, handsprayer, baskom, belender, timbangan, kamera, buuku milimeterr blok.

\section{Rancangan Penelitian}

Penelitian menggunakan Rancangan Acak Lengkap dengan faktor tunggal yaitu pestisida nabati ekstrak bandotan (B) dengan 5 taraf dan 8 ulangan :

$$
\begin{aligned}
\mathrm{b}_{0}= & \text { tanpa larutan ekstrak bandotan } \\
& \text { sebagai kontrol } \\
\mathrm{b}_{1}= & 10 \mathrm{ml} \mathrm{L}^{-1} \\
\mathrm{~b}_{2}= & 20 \mathrm{ml} \mathrm{L}^{-1} \\
\mathrm{~b}_{3}= & 30 \mathrm{ml} \mathrm{L}^{-1} \\
\mathrm{~b}_{4}= & 40 \mathrm{ml} \mathrm{L}^{-1}
\end{aligned}
$$

\section{Prosedur Penelitian}

\section{Penanaman Lobak di Polibag}

a. Penyiapan media tanam

Media tanam yang digunakan adalah tanah top soil, arang sekam dan pupuk kendang. Tanah top soil diambil dari lokasi peletakkan polybag dan arang sekam serta pupuk kendang dibeli di toko pertanian.

b. Pengisian media tanam

Media tanam dicampur merata dengan perbandingan 2:1:1 lalu digemburkan dan dimasukkan kedalam polibag berukuran $35 \times 35 \mathrm{~cm}$.

c. Persemaian

Persemaian dilakukan di sekitar lokasi peletakkan polybag. Persemaian menggunakan media tanam yang sama dengan media tanam pada polybag penanaman. Media yang digunakan untuk persemaian adalah daun pisang, karena dapat menghemat biaya dan lebih mudah didapat. Setiap lubang pada persemaian dimasukkan 2 benih tanaman lobak. Lalu ditutup tipis tipis. Lalu disiram hingga lembab. Benih akan tumbuh selama kurang lebih 5-6 hari.

d. Pemeliharaan

Pemeliharaan yang dilakukan yaitu: penyiraman, pemupukan, penyiangan gulma, dan pengendalian hama dan penyakit tanpa perlakuan insektisida. 
Pembuatan Ekstrak Bandotan (A.conyzoides L.)

Menyediakan bahan ekstrak yaitu Bandotan sebanyak $500 \mathrm{~g}$ yang diperoleh dari pekarangan rumah dan lahan penelitian. Selanjutnya Bandotan dicuci bersih dengan air, kemudian diblender dengan mencampur air sebanyak 1 liter. Larutan ekstrak yang telah diblender disimpan selama 3 hari agar selama penyimpanan terjadi proses fermentasi pada ekstrak Bandotan. Larutan yang sudah disimpan kemudian disaring agar tidak terdapat kotoran pada ekstrak Bandotan. Ekstrak yang sudah jadi dimasukkan ke dalam botol yang bersih agar ekstrak yang dihasilkan baik, dan botol yang telah diisi ekstrak ditutup kembali agar tidak terjadi kontaminasi. Ekstrak siap digunakan sesuai dengan perlakuan yaitu kontraol $\left(b_{0}\right)$, $10 \mathrm{ml} \mathrm{L}^{-1}\left(\mathrm{~b}_{1}\right), 20 \mathrm{ml} \mathrm{L}^{-1}\left(\mathrm{~b}_{2}\right), 30 \mathrm{ml} \mathrm{L}^{-1}\left(\mathrm{~b}_{3}\right)$, dan $40 \mathrm{ml} \mathrm{L}^{-1}\left(\mathrm{~b}_{4}\right)$.

Pelaksanaan Perlakuan
Aplikasi ekstrak sesuai perlakuan dilakukan pada saat tanaman berumur 14 dan 28 hari setelah tanam pada sore hari. Aplikasi dilakukan pada pukul 16.00 - 17.00 Wita dengan cara disemprotkan pada ke seluruh tubuh tanaman.

\section{Pengamatan dan Pengumpulan Data Frekuensi serangan hama}

Frekuensi serangan hama (FS) pada suatu tanaman dihitung menggunakan rumus sebagai berikut :

$$
\mathrm{FS}=\frac{\mathrm{X}}{\mathrm{Y}} \times 100 \%
$$

Keterangan :

$\mathrm{X}$ : Jumlah daun tanaman yang terserang.

$\mathrm{Y}$ : Jumlah daun tanaman yang diamati

Penilaian terhadap tingkat serangan berdasarkan persentase tanaman terserang menurut Syahrawi dan Busniah (2009), seperti disajikan pada Tabel 1.

Tabel 1. Penilaian terhadap persentase serangan hama pada tanaman Lobak

\begin{tabular}{cc}
\hline Persentase & Klasifikasi tingkat serangan \\
\hline$<10$ & Sangat rendah \\
$10-50$ & Rendah \\
$51-75$ & Sedang \\
$>75$ & Tinggi \\
\hline
\end{tabular}

Sumber : Syahrawi dan Busniah (2009)

\section{Intensitas serangan}

Intensitas serangan diamati pada saat 10 minggu setelah tanam, besarnya intensitas serangan dapat dihitung dengan menggunakan rumus sebagai berikut :

Keterangan :

$$
\mathrm{I}=\frac{\sum \mathrm{n} \times \mathrm{V}}{\mathrm{Z} \times \mathrm{N}} \times 100 \%
$$

I : Intensitas serangan

$\mathrm{N}$ : Jumlah daun yang terserang tiap kategori

$\mathrm{V}$ : Nilai numerik pada setiap kategori serangan

$\mathrm{Z}$ : Nilai numerik dari intensitas serangan tertinggi

$\mathrm{N} \quad$ : Jumlah daun yang diteliti

Nilai skala penelitian intensitas serangan berdasarkan persentase tanaman yang terserang, seperti disajikan pada Tabel 2. 
Tabel 2. Nilai Skala Untuk Setiap Kategori Serangan

\begin{tabular}{cc}
\hline Nilai Skala $(\mathrm{Z})$ & Kategori Serangan \\
\hline 0 & Tidak ada kerusakan pada daun tanaman \\
1 & Rusak ringan $\leq 25 \%$ \\
2 & Rusak sedang $>25 \%-50 \%$ \\
3 & Rusak Berat $>50 \%$ \\
4 & Rusak sangat berat $>75 \%-100 \%$ \\
\hline
\end{tabular}

\section{Analisis Data}

Untuk mengetahui pengaruh perlakuan digunakan sidik ragam. Bila hasil sidik ragam terhadap berpengaruh nyata atau sangat nyata (F.hitung > F.tabel 5 atau 1\%), maka untuk membandingkan dua rata-rata perlakuan dilakukan dengan Uji Beda Nyata Terkecil taraf 5\%. Rumus umum uji nyata BNT disajikan sebagai berikut :

BNT $5 \%=\mathrm{T}_{\text {tabel }}(\alpha, \mathrm{db}) \times \sqrt{\frac{2(\text { KTGalat })}{r}}$

Keterangan :

$\mathrm{T}_{\text {tabel }} \quad$ : Nilai $\mathrm{T}_{\text {tabel }}$ (pada $\alpha=5 \%$ dengan derajat bebas galat)

KT galat : Kuadrat tengah galat

$$
\begin{array}{ll}
\mathrm{R} & \text { : Ulangan } \\
\mathrm{t} & \text { : Perlakuan }
\end{array}
$$

\section{HASIL DAN PEMBAHASAN}

\section{Frekuensi Serangan \\ Frekuensi Serangan Umur 21 Hari Setelah Tanam}

Hasil sidik ragam menunjukkan bahwa pemberian ekstrak Bandotan berpengaruh nyata terhadap frekuensi serangan hama Plutella xylostella L. pada tanaman lobak umur 21 hari setelah tanam. Data rataan hasil penelitian disajikan pada Tabel 3.

Tabel 3. Uji Efikasi Ekstrak Bandotan terhadap Rata-rata Frekuensi Serangan Hama (Plutella xylostella L.) pada Tanaman Lobak Umur 21 Hari Setelah Tanam (\%).

\begin{tabular}{ccc}
\hline Perlakuan Ekstrak & Rata-rata & Tingkat \\
Bandotan $(\mathrm{b})$ & Frekuensi Serangan $(\%)$ & Serangan Tanaman \\
\hline Kontrol $\left(\mathrm{b}_{0}\right)$ & $20,13 \mathrm{~b}$ & Rendah \\
$10 \mathrm{ml} \mathrm{L}^{-1}\left(\mathrm{~b}_{1}\right)$ & $19,60 \mathrm{~b}$ & Rendah \\
$20 \mathrm{ml} \mathrm{L}^{-1}\left(\mathrm{~b}_{2}\right)$ & $5,35 \mathrm{a}$ & Sangat Rendah \\
$30 \mathrm{ml} \mathrm{L}^{-1}\left(\mathrm{~b}_{3}\right)$ & $3,46 \mathrm{a}$ & Sangat Rendah \\
$40 \mathrm{ml} \mathrm{L}^{-1}\left(\mathrm{~b}_{4}\right)$ & $2,27 \mathrm{a}$ & Sangat Rendah \\
\hline
\end{tabular}

Keterangan: Angka rata-rata yang diikuti oleh huruf yang sama pada kolom yang sama berarti berbeda tidak nyata berdasarkan hasil uji BNT taraf 5\% (BNT $=15,35)$.

Hasil pengamatan menunjukkan bahwa rata-rata pemberian ekstrak bandotan memberikan pengaruh nyata terhadap frekuensi serangan Hama Plutella xylostella L. pada tanaman lobak umur 21 hari setelah tanam (HST). Frekuensi serangan tertinggi terdapat pada perlakuan $b_{0}$, yaitu $20,13 \%$ dan yang terendah terdapat pada perlakuan $\mathrm{b}_{4}$, yaitu $2,27 \%$.

\section{Frekuensi Serangan Umur 35 Hari Setelah Tanam}

Hasil sidik ragam menunjukkan bahwa pemberian ekstrak Bandotan berpengaruh sangat nyata terhadap frekuensi serangan hama Plutella xylostella L. pada tanaman lobak umur 35 hari setelah tanam. Data rataan hasil penelitian disajikan pada Tabel 4. 
Tabel 4. Uji Efikasi Ekstrak Bandotan (Ageratum conyzoides L.) terhadap Rata-rata Frekuensi Serangan Hama (Plutella xylostella L.) pada Tanaman Lobak Umur 35 Hari Setelah Tanam $(\%)$.

\begin{tabular}{ccc}
\hline Perlakuan Ekstrak & Rata-rata & Tingkat \\
Bandotan $(\mathrm{b})$ & Frekuensi Serangan $(\%)$ & Serangan Tanaman \\
\hline Kontrol $\left(\mathrm{b}_{0}\right)$ & $18,5 \mathrm{~b}$ & Rendah \\
$10 \mathrm{ml} \mathrm{L}^{-1}\left(\mathrm{~b}_{1}\right)$ & $10,8 \mathrm{ab}$ & Sangat Rendah \\
$20 \mathrm{ml} \mathrm{L}^{-1}\left(\mathrm{~b}_{2}\right)$ & $5,0 \mathrm{a}$ & Sangat Rendah \\
$30 \mathrm{ml} \mathrm{L}^{-1}\left(\mathrm{~b}_{3}\right)$ & $2,5 \mathrm{a}$ & Sangat Rendah \\
$40 \mathrm{ml} \mathrm{L}^{-1}\left(\mathrm{~b}_{4}\right)$ & $1,6 \mathrm{a}$ & Sangat Rendah \\
\hline
\end{tabular}

Keterangan: Angka rata-rata yang diikuti oleh huruf yang sama pada kolom yang sama berarti berbeda tidak nyata berdasarkan hasil uji BNT pada taraf 5\% $(\mathrm{BNT}=8,26)$.

Hasil uji BNT taraf 5\% pada pemberian ekstrak bandotan menunjukkan bahwa perlakuan $b_{1}, b_{2}, b_{3}$ dan $b_{4}$ berbeda nyata dibandingkan dengan $b$. Frekuensi serangan tertinggi terdapat pada perlakuan $b_{0}$, yaitu $18,5 \%$ dan yang terendah terdapat pada perlakuan $\mathrm{b}_{4}$, yaitu $1,6 \%$.

Berdasarkan hasil penelitian di atas menunjukkan bahwa pemberian ekstrak bandotan dengan konsentrasi $40 \mathrm{ml} \mathrm{L}^{-1}$ dapat menekan tingkat frekuensi serangan hama Pluttella xylostela L. dibandingkan dengan konsentrasi ekstrak lainnya. Semakin tinggi konsentrasi ekstrak tanaman bandotan, maka semakin rendah tingkat frekuensi serangan hama yang terjadi pada tanaman lobak. Sesuai dengan pernyataan Sianiparm M.S., dkk.(2004) bahwa semakin tinggi konsentrasi insektisida maka kandungan senyawa aktifnya juga semakin tinggi, sehingga tingkat kematian yang ditimbulkan semakin besar. Hal ini membuktikan bahwa ekstrak tanaman bandotan dapat menekan tingkat frekuensi serangan hama Plutella xylostella L. pada tanaman lobak. Keadaan ini disebabkan Bandotan diketahui mengandung senyawa aktif yang dapat menekan perkembangan makan hama. Senyawa metabolit sekunder dalam bandotan yaitu, seperti flavonoid, alkaloid, terpena, kromen, kromon, benzofuran, kumarin, minyak atsiri, sterol dan tanin yang berpengaruh terhadap sistem saraf otot, keseimbangan hormon, reproduksi, perilaku berupa penolak, penarik, anti makan dan sistem pernafasan OPT. (Kamboj and Saluja, 2008). Dinata (2007) menyatakan bahwa flavonoid dapat dimanfaatkan sebagai bahan aktif dalam pembuatan insektisida nabati. Sedangkan alkaloid menurut Sanyoto (2003), merupakan senyawa pahit dan beracun dapat menyebabkan rasa pusing dan tidak mau makan daun sawi disebabkan rasanya yang pahit dan akhirnya mati. Lebih lanjut Samsudin (2008) menyatakan bahwa kandungan aktif tanaman bandotan adalah saponin, flavanoid dan polifenol mampu mencegah hama mendekati tanaman (penolak) dan mampu menghambat pertumbuhan larva menjadi pupa.

\section{Intensitas Serangan Intensitas Serangan Umur 21 Hari Setelah Tanam}

Hasil sidik ragam menunjukkan bahwa pemberian ekstrak Bandotan berpengaruh nyata terhadap intensitas serangan hama Plutella xylostella L. pada tanaman lobak umur 21 hari setelah tanam. Data rataan hasil penelitian disajikan pada Tabel 5. 
Tabel 5. Uji Efikasi Ekstrak Bandotan (Ageratum conyzoides L.) terhadap Rata-rata Intensitas Serangan Hama (Plutella xylostella L.) Pada tanaman lobak Umur 21 Hari Setelah Tanam $(\%)$.

\begin{tabular}{ccc}
\hline Perlakuan Ekstrak & Rata-rata & Tingkat \\
Bandotan $(\mathrm{b})$ & Intensitas Serangan $(\%)$ & Serangan Tanaman \\
\hline Kontrol $\left(\mathrm{b}_{0}\right)$ & $12,7 \mathrm{~b}$ & $\mathrm{RR}$ \\
$10 \mathrm{ml} \mathrm{L}^{-1}\left(\mathrm{~b}_{1}\right)$ & $12,5 \mathrm{~b}$ & $\mathrm{RR}$ \\
$20 \mathrm{ml} \mathrm{L}^{-1}\left(\mathrm{~b}_{2}\right)$ & $5,3 \mathrm{a}$ & $\mathrm{RR}$ \\
$30 \mathrm{ml} \mathrm{L}^{-1}\left(\mathrm{~b}_{3}\right)$ & $2,4 \mathrm{a}$ & $\mathrm{RR}$ \\
$40 \mathrm{ml} \mathrm{L}^{-1}\left(\mathrm{~b}_{4}\right)$ & $2,3 \mathrm{a}$ & $\mathrm{RR}$ \\
\hline
\end{tabular}

Keterangan: Angka rata-rata yang diikuti oleh huruf yang sama pada kolom yang sama berarti berbeda tidak nyata berdasarkan hasil uji BNT taraf 5\%. (BNT = 5,9). RR : Rusak Ringan.

\section{Intensitas Serangan Umur 35 Hari Setelah Tanam}

Hasil sidik ragam menunjukkan bahwa pemberian ekstrak Bandotan berpengaruh nyata terhadap intensitas serangan hama Plutella xylostella L. pada tanaman lobak umur 35 hari setelah tanam. Data rataan hasil penelitian disajikan pada Tabel 6.

Tabel 6. Uji Efikasi Ekstrak Bandotan (Ageratum conyzoides L.) terhadap Rata-rata Intensitas Serangan Hama (Plutella xylostella L.) pada Tanaman Lobak Umur 35 Hari Setelah Tanam $(\%)$.

\begin{tabular}{ccc}
\hline Perlakuan Ekstrak & Rata-rata & Tingkat \\
Bandotan $(\mathrm{b})$ & Frekuensi Serangan $(\%)$ & Rerangan Tanaman \\
\hline Kontrol $\left(\mathrm{b}_{0}\right)$ & $6,5 \mathrm{~b}$ & $\mathrm{RR}$ \\
$10 \mathrm{ml} \mathrm{L}^{-1}\left(\mathrm{~b}_{1}\right)$ & $3,1 \mathrm{ab}$ & $\mathrm{RR}$ \\
$20 \mathrm{ml} \mathrm{L}^{-1}\left(\mathrm{~b}_{2}\right)$ & $2,5 \mathrm{ab}$ & $\mathrm{RR}$ \\
$30 \mathrm{ml} \mathrm{L}^{-1}\left(\mathrm{~b}_{3}\right)$ & $1,2 \mathrm{a}$ & $\mathrm{RR}$ \\
$40 \mathrm{ml} \mathrm{L}^{-1}\left(\mathrm{~b}_{4}\right)$ & $0,6 \mathrm{a}$ & $\mathrm{R}$ \\
\hline
\end{tabular}

Keterangan: Angka rata-rata yang diikuti oleh huruf yang sama pada kolom yang sama berarti berbeda tidak nyata berdasarkan hasil uji BNT taraf 5\% $(\mathrm{BNT}=4,38)$. RR : Rusak Ringan.

Hasil uji BNT taraf 5\% pada pemberian ekstrak bandotan menunjukkan bahwa perlakuan $b_{1}, b_{2}, b_{3}$ dan $b_{4}$ berbeda nyata dibandingkan dengan $b_{0}$. Frekuensi serangan tertinggi terdapat pada perlakuan $b_{0}$, yaitu $6,5 \%$ dan yang terendah terdapat pada perlakuan $\mathrm{b}_{4}$, yaitu $0,6 \%$.

Hasil penelitian menunjukkan bahwa perlakuan ekstrak Bandotan berpengaruh nyata dan sangat nyata terhadap intensitas serangan umur 21 dan 35 hari setelah tanam. Intensitas serangan hama tertinggi terjadi pada tanaman kontrol. Pada tanaman yang diberikan ekstrak Bandotan tingkat intensitas serangan hama adalah sangat rendah hal ini disebabkan karena Bandotan mengandung metabolit sekunder seperti alkaloid dan terpenoid yang sangat berpotensi sebagai penghambat makan pada sejumlah serangga (Ayu, N.S.A, 2019) 
Tabel 7. Rekapitulasi Data Penelitian Uji Efikasi Ekstrak Bandotan (Ageratum conyzoides L.) Terhadap Frekuensi dan Intensitas Serangan Hama Ulat Plutella xylostella L. pada Tanaman Lobak

\begin{tabular}{lcccc}
\hline Perlakuan & Esktrak & \multicolumn{2}{c}{ Frekuensi Serangan $(\%)$} & \multicolumn{2}{c}{ Frekuensi Serangan $(\%)$} \\
\cline { 2 - 5 } Bandotan $(\mathrm{B})$ & $21 \mathrm{HST}$ & $21 \mathrm{HST}$ & $21 \mathrm{HST}$ & $35 \mathrm{HST}$ \\
\hline Hasil Sidik Ragam & $*$ & $* *$ & $*$ & $* *$ \\
Kontrol $\left(\mathrm{b}_{0}\right)$ & $20,13 \mathrm{~b}$ & $18,5 \mathrm{~b}$ & $12,7 \mathrm{~b}$ & $6,5 \mathrm{~b}$ \\
$10 \mathrm{ml} \mathrm{L}-1\left(\mathrm{~b}_{1}\right)$ & $19,60 \mathrm{~b}$ & $10,8 \mathrm{ab}$ & $12,5 \mathrm{~b}$ & $3,1 \mathrm{ab}$ \\
$20 \mathrm{ml} \mathrm{L}-1\left(\mathrm{~b}_{2}\right)$ & $5,35 \mathrm{a}$ & $5,0 \mathrm{a}$ & $5,3 \mathrm{a}$ & $2,5 \mathrm{ab}$ \\
$30 \mathrm{ml} \mathrm{L}-1\left(\mathrm{~b}_{3}\right)$ & $3,46 \mathrm{a}$ & $2,5 \mathrm{a}$ & $2,4 \mathrm{a}$ & $1,2 \mathrm{a}$ \\
$40 \mathrm{ml} \mathrm{L}-1\left(\mathrm{~b}_{4}\right)$ & $2,27 \mathrm{a}$ & $1,6 \mathrm{a}$ & $2,3 \mathrm{a}$ & $0,6 \mathrm{a}$ \\
\hline
\end{tabular}

Keterangan : * - Berpengaruh Nyata; $* *=$ berpengaruh sangat nyata; dan HST : hari setelah Tanam

Pada pengamatan selama 14 hari menunjukkan intensitas serangan berkurang. Hal ini membuktikan bahwa ektrak dari Bandotan mampu membunuh hama dalam jangka waktu yang relatif cepat. Pestisida nabati dapat mengendalikan serangan hama dan penyakit melalui cara kerja yang unik, yaitu dapat melalui perpaduan beberapa cara atau secara tunggal. Cara kerja sangat spesifik yaitu: merusak perkembangan, telur,larva dan pupa, penolak makan, menghambat reproduksi serangga betina hama, mengusirserangga dan menghambat penggantian kulit serangga (Solikin, 2011). Berdasarkan hasil pengamatan, intensitas serangan hama pada tanaman lobak antara perlakuan $b_{1}, b_{2}, b_{3}$, dan $b_{4}$ adalah berbeda nyata dibandingkan dengan perlakuan $b_{0}$, teapi diantara perlakuan $b_{2}, b_{3}$ dan $b_{4}$ adalah berbeda tidak nyata. Hal ini menunjukkan bahwa reaksi serangga terhadap pestisida nabati tertentu tergantung pada konsentrasinya. Penghambatan total oleh suatu senyawa anti makan terjadi pada kisaran konsentrasi efektif tertentu, dimana perlakuan ekstrak Bandotan 10, 20,30 dan $40 \mathrm{ml} \mathrm{L}^{-1}$ berbeda dengan perlakuan ekstrak $0 \mathrm{ml}$ (kontrol). Hal ini membuktikan bahwa semakin tinggi konsentrasi ekstrak bandotan maka tingkat kerusakan tanaman lobak semakin rendah.

\section{KESIMPULAN DAN SARAN}

\section{Kesimpulan}

Berdasarkan hasil penelitian maka dapat disimpulkan hal sebagai berikut :

1. Perlakuan ekstrak Bandotan berpengaruh nyata sampai sangat nyata terhadap frekuensi serangan hama umur 21 dan 35 hari setelah tanam, serta terhadap intensitas serangan hama umur 21 dan 35 hari setelah tanam.

2. Ekstrak Bandotan bersifat sebagai insektisida alami terhadap ulat Pluttella xylostella L, semakin tinggi konsentrasi ekstrak yang diberikan maka semakin rendah frekuensi dan intensitas serangan hama Pluttela xylostella $\mathrm{L}$ pada tanaman lobak.

3. Konsentrasi Ekstrak bandotan yang dapat menekan ulat Pluttella xylostella L. terdapat pada konsentrasi $40 \mathrm{ml} \mathrm{L}^{-1}$ $\left(b_{4}\right)$.

\section{Saran}

Dengan adanya hasil penelitian ini, diharapkan dapat memberikan informasi bagi semua pihak bahwa tanaman babadotan dapat digunakan sebagai insektisida yang ramah lingkungan. Diharapkan adanya penelitian lebih lanjut mengenai pengaruh ekstrak babadotan terhadap jenis serangga lainnya. 


\section{DAFTAR PUSTAKA}

Agromedia, 2008. Buku Pintar Tanaman Obat, 431 Jenis Tanaman Penggempur Aneka penyakit, Agromedia Pustaka, Jakarta.

Anonim, 2012. "Info Hama \& Penyakit Tumbuhan : Plutella xylostella L." http://infohamapenyakittumbuhan.blog spot.com/2012/03/plutella-xylostellaulat-kubis.htm?m=1 (Diakses, pada 20 Januari 2020).

Anonim, 2012. "Ulat Kubis Plutella xylostella"

http://blog.ub.ac.id/proteksitanaman/20 12/09/25/ulta-kubis-plutella-xylostella/ (Diakses, pada 20 Januari 2020).

Badan Litbang Pertanian. 2011. Daun Gamal (Gliricidia sepium) Obat Scabies pada Kambing. Sinar Tani, Edisi 30 Maret5 April 2011 No.3399 Tahun XLI.

Badan POM RI, 2008. Ageratum conyzoides L. Badan POM RI, Direktorat Obat Asli Indonesia, Jakarta.

Dadang dan Prijono, 2008. Insektisida Nabati: Prinsip, Pemanfaatan, dan Pengembangan, Departemen Proteksi Tanaman. IPB, Bogor.

Damayanti, E, 2006. Pengaruh Ekstrak Daun Babandotan (Ageratum conyzoides L.) sebagai Insektisida Botani terhadap Mortalitas dan Perkembangan Ulat Kubis (Plutella xylostella L.), Skripsi, Prodi Pendidikan Biologi, JPMIPA, FKIP Univ, Jember.

Gunawan dan Mulyani. 2004. Ilmu Obat Alam. Penebar Swadaya, Jakarta.

Harbone, JB., 1996. Phytochemical Methods (diterjemahkan oleh Padmawinata K., Soediro I, ITB, Bandung.

Hastuti, D., A.Mujib, dan A.S. Mohamad. 2014. Uji Efektifitas Larutan Pestisida Nabati terhadap Hama Ulat Krop (Crocidolomia pavonana L.) pada Tanaman Kubis (Brassica oleraceae) Jurusan Agroekoteknologi, Faperta, Universitas Sultan Ageng Tirtayasa, Serang Banten.

Julaily, N., dan Mukarlina, T. R. S., 2013. Pengendalian Hama pada Tanaman Sawi (Brassica juncea L.) Menggunakan Ekstrak Daun Pepaya (Carica papaya L.). protobiont, 2(3).

Kamboj, A. dan Saluja. 2010. Ageratum conyzoides L.: A Review on its Phyctochemical and Pharmacological Profile. International Jounal of Green Pharmacy, 59-68. 